\title{
Spondilotorasik Tip Jarcho-Levin Sendromu: Yenidoğan Olgu Sunumu
}

\author{
Abdurrahman Avar Özdemir ${ }^{1}$, Aydın Varol ${ }^{1}$
}

\begin{abstract}
ÖZET:
Spondilotorasik tip Jarcho-Levin Sendromu: Yenidoğan olgu sunumu Jarcho-Levin Sendromu kısa torax, kosta ve vertebraların yapısal ve sayısal anomalileri ile karakterize nadir bir sendromdur. Spondilotorasik ve spondilokostal dizostoz olarak adlandırılan iki gruba ayrılan bu sendroma diğer sistemlere ait anomalilerde eşlik edebilmektedir. Bu yazıda Jarcho-Levin Sendromu tanısı alan bir yenidoğan olgusu ciddi nörolojik tutulumu ve eşlik eden anomalileri nedeniyle sunulmuştur.

Anahtar kelimeler: Chiari tip2, meningomyelosel, spondilotorasik disostoz, yenidoğan

ABSTRACT:

Spondylothoracic type Jarcho-Levin Sydnrome: a neonatal case presentation Jarcho-Levin Syndrome is a rare syndrome, characterized by short thorax, numerical and structural abnormalities of costae and vertebrae. This syndrome, divided into spondylothoracic and spondylocostal subgroups, can be accompanied by other system abnormalities. Herein, we present a newborn diagnosed with Jarcho-Levin syndrome with serious neurological symptoms and accompanied abnormalities.
\end{abstract}

Key words: Spondylothoracic dysostosis, chiari type 2, meningomyelocele, newborn

Ş.E.E.A.H. Tıp Bülteni 2015;49(3):228-30

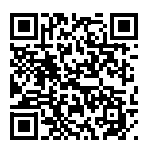

'Medicine Hospital, Yenidoğan Yoğun Bakım Ünitesi, Güneşli, İstanbul - Türkiye

Yazışma Adresi / Address reprint requests to: Abdurrahman Avar Özdemir,

Medicine Hospital, Yenidoğan Yoğun Bakım Ünitesi, Güneşli, İstanbul - Türkiye

Telefon / Phone: +90-532-367-4581

E-posta / E-mail:

avarozdemir@gmail.com

Geliş tarihi / Date of receipt: 22 Aralık 2014 / December 22, 2014

Kabul tarihi / Date of acceptance: 18 Ocak 2015 / January 18, 2015

\section{GiRiş}

İlk kez 1938 yılında Jarcho ve Levin tarafından tanımlanan Jarcho-Levin Sendromu (Omim \#277300ICD+) sıklıkla otozomal resesif (OR) kalıtım göstermektedir (1-3). Bu sendrom için prevalans 0,25/10000 olarak bildirilmektedir (4). Kısa gövde ve kısa göğüs kafesinin yengeç benzeri görünümü, kısa ve yassı kosta, hemivertebra, yarık vertebra, kelebek vertebra, vertebral ve kostal füzyon, sayısal anomaliler sendromun temel özelliklerini tanımlamakla birlikte, sinir sistemi, kardiyak, üriner ve gastrointestinal sistemi ilgilendiren bir çok anomali bu sendromda görülebilmektedir (1-5). Spondilokostal ve spondilotorasik olmak üzere iki alt gruba ayrılmakta, spondilotorasik tipte mortalite çok daha fazla görülmektedir. Hastaların çoğu solunum yetmezliği, enfeksiyon ya da eşlik eden anomaliler nedeniyle kaybedilmektedir (4,5-8).

Makalemizde chiari tip 2 malformasyonu, hidro- sefali, meningomyelosel, kaudal regresyon gibi sinir sistemi anomalileri bulunan, diğer sistem anomalilerinin de eşlik ettiği spondilotorasik tip Jarcho-Levin Sendromu olgusu sunulmuştur.

\section{OLGU}

Yirmi altı yaşındaki annenin 4. gebeliğinden, 38 gebelik haftasında sezaryen ile doğan erkek bebeğin 1. ve 5.dakika Apgarı sırasıyla 4 ve 7 olarak saptandı. Solunum sıkıntısı ve ağır sinir sistemi anomalisi nedeniyle yenidoğan yoğun bakım ünitesine yatırıldı.

Gebeliği süresince takipli iken gebeliğin 18. haftasında saptanan anomaliler nedeniyle aile bilgilendirilmiş ancak aile gebeliğin sonlandırılmasını kabul etmemişti. Gebelikte ilaç kullanımı, hastalık öyküsü yoktu, anne düzenli olarak folik asit almıştı. Aile öyküsünde akrabalık veya benzer bir olgu mevcut değildi.

Olgumuzun doğum ağırlığı 2880 gr (25-50. persen- 
til), boyu $35 \mathrm{~cm}(<3$. persentil), baş çevresi $40 \mathrm{~cm}(>90$. persentil) idi. Fizik muayenesinde makrosefali, geniş ön ve arka fontanel, suturalar arası açık, frontal bölgede genişlik, dil büyük, burun kökü basık, boyun kısa, gövde ve göğüs kafesi kısa, güvercin göğüs görünümü mevcut, açıklığı sağa bakan skolyoz, torakolomber bölgede kesesi açılmış meningomyelosel, bilateral solda daha büyük inguinal herni, anal darlık, bilateral pes ekinovarus deformitesi ve sol ayak bileği üzerinde şerit şeklinde bası izi bulunmaktaydı (Resim 1,2).

Hastaya solunum sıkıntısı nedeniyle başlık ile oksijen desteği, bütünlüğü bozulmuş meningomyelosel kesesi nedeniyle antibiyotik tedavisi başlandı. Hemogram, CRP, kan gazı ve diğer biyokimyasal değerler normal sınırlardaydı. Akciğer ve iskelet grafilerinde normalden küçük akciğer ve göğüs kafesi boyutları, deforme, genişlemiş yengeç şeklinde göğüs kafesi görünümü, sağda 1. ve 2. kostada arkada füzyon, solda 1.ve



Resim 1: Olgunun genel görünümü

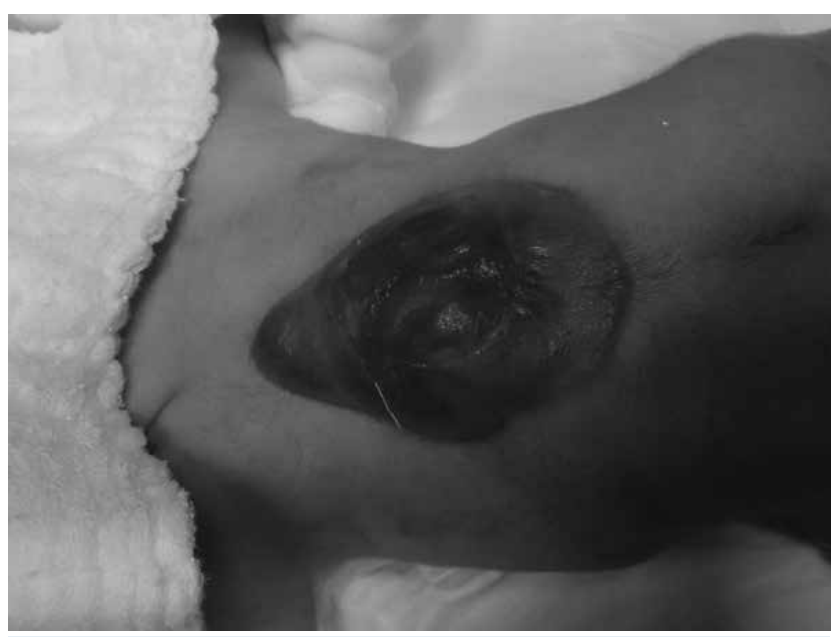

Resim 2: Eşlik eden büyük boyutlu meningomiyelosel

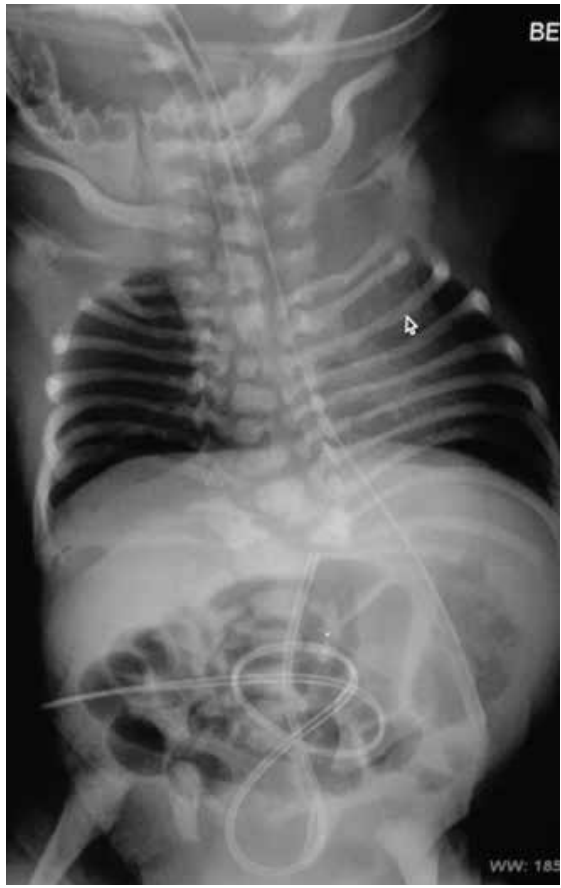

Resim 3: Olgunun kostavertebral bölge grafisi

2. kostada önde füzyon vardı. Sağda 9, 10 ve 12. kosta mevcut değildi. Açıklığı sağa bakan skolyoz, servikal 7. vertebrada kelebek vertebra, torakal 3-5. vertebrada hemivertebra, torakal 6-7. vertebrada kelebek vertebra, lumbosakral bölgede agenezi (kaudal regresyon sendromu) görülmekte idi (Resim 3). Kranial tomografide chiari tip 2 malformasyonu, hidrosefali, serebral parankimde incelme saptandı. Ekokardiyografide patent foramen ovale dışında özellik yoktu. Olgunun batın ultrasonografisinde ise sağ böbrek küçüktü ve pelvikaliektazi (sağ renal pelvis $9 \mathrm{~mm}$ ) saptandı. İzleminde solunum sıkıntısı gerileyen ve genel durumu nispeten düzelen olgu açık meningomyelosel kesesi nedeniyle erken ameliyat edildi. Ameliyat sonrası solunum sıkıntısı artan yenidoğan bebeğe pozitif basınçlı ventilasyon desteği başlandı. Genel durumu giderek bozulan olgu 6. gününde solunum yetmezliği nedeniyle kaybedildi.

\section{TARTIŞMA}

Jarcho-Levin Sendromu günümüzde omurga ve göğüs kafesini tutan tüm disostozları içerse de özellikle spondilotorasik tip disostozu tanımlamak için kullanılır (1-4). Bu sendromun klinik sınıflandırması ile ilgili farklı görüşler bulunsa bile genellikle spon- 
dilotorasik ve spondilokostal olmak üzere iki gruba ayrılmakta olup spondilokostal grubun kendi içinde tip 1 ve tip 2 olmak üzere iki alt grubu bulunmaktadır (5). Bizim vakamızın içinde bulunduğu grup olan spondilotorasik tipde daha ağır vertebra ve göğüs kafesi anomalileri bulunmakta ve mortalite hızı \%44-45 olarak bildirilmektedir $(1,8)$.

Literatürde sporadik, OR ve OD kalıtım bildirilmiş olmasına rağmen vakaların çoğu OR kalıtım göstermektedir. Spondilotorasik tipde vakaların çoğu OR kalıtılan MESP2 genindeki mutasyona bağlı olarak ortaya çıkmaktadır $(2,5)$. Puerto Riko ve İspanyol kökenlilerde ailesel olgulara daha sık rastlanmaktadır ve olguların \%90'ında MESP2 gen mutasyonu mevcuttur (1-3,5). Spondilokostal tipdeki kalıtım şekli de OR'dir ve SCDO1-4 genlerindeki mutasyon sonucu ortaya çıkmaktadır. Bunlar arasında en sık etkilenen SCDO1 (DLL3) genidir $(2-4,8)$.

Bizim vakamızda ailede benzer bir öykü yoktu ve akraba evliliği bulunmamaktaydı. Sık olmamakla beraber ailesel kalıtım gösterdiği için genetik danışma önerildi ancak ebeveynler tarafından kabul edilmedi.

Oluşum mekanizması tam olarak aydınlatılamamış olsa da intrauterin hayatın ilk 6 haftasında defektif embriyonik indüksiyon sonucu oluştuğu, 4-5. haftalarda somitlerdeki yetersiz segmentasyonun vertebra anomalilerine, notakordal vertebra kıkırdağındaki anormal gelişimin kostal deformitelere yol açtığı düşünülmektedir $(5,9)$.

Sıklıkla rastlanan iskelet deformiteleri hemiver- tebra, hipoplastik vertebra, yarık vertebra, vertebral füzyon, kelebek vertebra, kostalarda sayısal anomaliler, füzyon, asimetri, şekil bozuklukları, yengeç görünümlü göğüs kafesi, kısa gövde, kısa boy, frontal belirginleşme, kısa boyun, pes ekinovarus benzeri alt extremite anomalileridir (1,2,5). Bizim vakamızda kısa boy, kısa gövde, kısa boyun, frontal belirginleşme, skolyoz, vertebralarda hemivertebra ve kelebek vertebra, lumbosakral bölgede vertebralarda sayısal eksiklik, kostalarda füzyon ve sayısal eksiklik, yengeç görünümlü göğüs kafesi ve alt extremitelerde bilateral pes ekinovarus bulunmaktaydı.

Jarcho-Levin Sendromunda vertebral ve kostal anomalilere ek olarak nöral tüp defekti (NTD) görülebilmektedir. Tüm toplumda NTD sıklığı \%1-2 olarak bildirilmekle beraber bu sendromda görülme sıklığı \%25'e kadar çıkmaktadır (1,3,4,9-11). Bizim vakamızda torakolomber bölgede büyük meningomyelosel $(12 \times 8 \mathrm{~cm})$, chiari tip 2 malformasyonu ve hidrosefali bulunmaktaydı.

Jarcho-Levin Sendromunda bu bulgulara ek olarak kardiyak, üriner ve gastrointestinal sistem anomalileri de görülebilmektedir $(2,3,8,12)$. Olgumuzda sağ böbrek küçüktü ve renal pelvikaliektazi vardı. Bilateral inguinal herni, anal darlık diğer bulgulara eşlik etmekteydi.

Bu yazıda spondilotorasik tip Jarcho-Levin Sendromu tanısı alan yenidoğan olgusu güncel literatür bilgilerinin ışığında ağır nörolojik tutulumu ve diğer sistem anomalilerinin eşlik etmesi nedeniyle sunulmuştur.

\section{KAYNAKLAR}

1. Jarcho S, Levin PM. Hereditary malformation of the vertebral bodies.Johns Hopkins Hosp 1938; 62: 216-26.

2. Jones KL. Miscellaneous syndromes. In: Jones $K L$, Jones $M C$, Casanelles M (eds). Smith's Recognizable Patterns of Human Malformation. $7^{\text {th }}$ edition. Phladelphia: Elsevier Saunders; 2013, p. 782-3.

3. Kulkarni ML, Navaz S, Vani HN, Manjunath KS, Matani D. Jarcho Levin Syndrome. Indian Journal of Pediatrics 2006; 73: 245-7.

4. Güzoğlu N, Dilli D, Oğuz SŞ, Kızılelma A, Erdeve Ö, Ceylaner $S$ ve ark. Nöral tüp defektinin eşlik ettiği spondilotorakal tip Jarcho-Levın Sendromu: Bir olgu sunumu.Ankara Üniversitesi Tıp Fakültesi Mecmuası 2010; 63: 65-7.

5. Aydın H, Çifçi E, Hekimoğlu B. Jarcho-Levın Sendromu: Spondilokostal Displazili yenidoğanda direkt grafi bulguları. Yeni Tıp Dergisi 2008; 25: 245-7.

6. Sharma AK, Phadke SR, Halder A, Agarwal SS. Jarcho-Levin Syndrome. Indian Pediatrics 1994; 31: 707-8.

7. Çıraklı A, Erdoğan M, Çıraklı S, Hicabi S, Çelik FÇ, Aygün C. Jarcho-Levin Sendromlu yenidoğanda bilateral femur kırı̆̆ı: Olgu sunumu. Joop Derg 2013; 5: 145-7.

8. Akın MA, Güneş T, Baykan A,Çoban D, Sezer S, Vatankulu F. Aynı olguda iki nadir hastalık: Jarcho-Levin Sendromu ve komplex kardiyak patoloji. Turkish J Pediatr Dis 2010; 4: 104-8.

9. Odacı E, Yıldıran A, Küçüködük Ş, Çiftçi N. Abnormalities may be related defective somitogenesis: multiple vertebral segmentation defects and neural tube defects. O.M.Ü. Tıp Dergisi 2001; 18: 216-24.

10. Çalık M, Abuhandan M, İscan A, Dertlioğlu SB, Çeçe H. Servikal spina bifida ve Chiari tip 2 malformasyonu birlikteliği: Bir olgu sunumu. Tıp Araştırmaları Dergisi 2013; 11: 8-11.

11. Gedikbaşı A, Yıldırım G, Bingöl B, ismayilzade R, Çelikkol Ö, Ceylan Y. Nöral Tüp Defekti ve iniensefali ile komplike olmuş Jarcho-Levin sendromu. Jopp Derg 2010; 2: 89-92.

12. Mittal A, Binit S, Mittal M, Aggarwal KC. Jarcho-Levin Syndrome with Sprengel's Deformity: a rare entity. Med J Dy Patil Univ (serial online) 2014; 7: 408-9. 